\title{
COMMENTARY
}

\section{Completing the Academic Leadership Fellows Program during the pandemic}

\author{
Matthew A. Wanat, PharmD ${ }^{\mathrm{a}, \mathrm{b}}$ \\ ${ }^{a}$ University of Houston, College of Pharmacy, Houston, Texas \\ ${ }^{\mathrm{b}}$ Editorial Board Member, American Journal of Pharmaceutical Education, Arlington, Virginia
}

Corresponding Author: Matthew A. Wanat, University of Houston, College of Pharmacy, 4849 Calhoun Rd., Houston, TX 77204. Tel: 832-842-8367. Email: MAWanat@uh.edu

Submitted August 18, 2021; accepted September 9, 2021; ePublished September 2021

The COVID-19 pandemic caused the Academic Leadership Fellows Program to shift to a virtual format for Cohort 17. Major differences compared to previous years included changes in networking strategies among fellows, lack of in-person team building activities, and the preparation and delivery of the team debates. Adaptations in fellow peer interactions and learning approach proved strong relationships and collaborations can be formed in a virtual setting. Concurrent mentorship and leadership opportunities at the fellows home institution remains a fundamental component of the program to enhance personal growth. The ALFP program proved that it can still deliver a meaningful professional development opportunity for faculty leaders in a virtual setting.

Keywords: professional development, leadership, education, academia

\section{INTRODUCTION}

Like many in the academy I can clearly remember receiving my first offer letter for a faculty position. With the offer letter came a request for what I desired as part of my start-up package. At the time I was finishing a PGY2 residency and making the transition into a faculty role, so I researched unique professional development opportunities that would help me grow as an academician. The Academic Leadership Fellows Program (ALFP) caught my attention as a great opportunity to learn, network, and reflected on how I wanted to lead. My department chair liked the idea but informed me to get the most out of the program I needed more academic and leadership experience prior to completing the program. Nine years later as a faculty member I was given the opportunity to complete the ALFP program. Although it was conducted virtually because of the pandemic, it delivered on everything that I envisioned it would.

The ALFP program was implemented in 2005 by the American Association of Colleges of Pharmacy (AACP) to help develop academic pharmacy leaders needed to meet the growing changes within the academy. I was part of cohort 17, which ran from September 2020 to July 2021. The year-long development program traditionally includes four inperson sessions, with two of them incorporated into the AACP annual and interim meeting programming. The ALFP curriculum focuses on personal leadership development, team building, adapting to change, and current issues in higher education, among other topics. Each cohort has 30 fellows, consisting of faculty leaders from different colleges of pharmacy throughout the country. Fellows are grouped into teams of 5-6 and paired up with a Dean mentor. Cohort 17 of ALFP was conducted virtually via Zoom and breakout rooms for all sessions.

\section{Program Differences During the Pandemic}

Feedback that I received from past participants of ALFP indicated the greatest strength of the program were the relationships formed among the co-fellows. I thought the virtual format would definitely present a challenge in building these relationships. I found that I had to be more purposeful and focused in making sure that I was fully engaged and participating virtually. This included proactively introducing myself to new fellows and trying to break the ice and get to know them and their story through the computer. Virtual programming can be a difficult venue for interaction and building relationships, but I think our cohort quickly found out that the virtual format would not stop a group of highly motivated individuals from getting the most out of the opportunity. We were able to connect over our experiences handling COVID at our home institutions and share stories and advice for handling difficult scenarios. There was more than enough to talk about, and I never felt the awkward silence that can be common when virtual. The relationships formed with my team of co-fellows and dean mentor were the strongest because we were frequently placed in breakout rooms together for active learning activities. One large difference with the virtual format compared to in-person was the decreased time spent with other fellows outside of my team. 
The part of the ALFP program that I felt was most impacted by the virtual format were the in-person team building activities. Although several different team building activities were transitioned to virtual, some activities such as the ropes course and visit to Mt. Vernon were not able to happen. Additional social opportunities, such as dinners and gatherings at the meetings did not occur either. We scheduled virtual social hours several times to connect after work and catch up on non-work related topics. These were positive experiences that gave each of us the opportunity to interact outside the work setting and get to know each other on a more personal level. However, these virtual gatherings can't replace these opportunities in person. The ALFP administrative staff have coordinated a future in-person event for our cohort to network, team-build, and formally have our graduation from the program, which I am excited for.

The primary deliverable for the ALFP is a team debate that occurs as part of the interim AACP meeting. Although we received training and team coaching sessions from a professional debater, the debate was easily the most stressful part of ALFP. The virtual format not only changed how we were able to prepare before the debate, but also the team collaboration and discussion that occurs during the debate. A large portion of the debate efforts occur in the form of response and rebuttal to counter-points the opposing team makes. Our team had to rely on text messaging to relay thoughts and ideas to the next speaker, which was more difficult than consulting with each other in person as the debate occurred. The debates also involved audience participation to provide thoughts and questions on the topics. Breakout rooms worked well to generate audience feedback and discussion. The sessions where the audience was able to participate generated many new ideas, and could be provided additional time when scheduling future debates. Debate topics for Cohort 17 included whether mandatory diversity committees can drive change in the academy, whether academia's response to COVID was a model for future pandemics, and if pharmacy curricula should include additional entrepreneurship training for students. The debates pushed us out of our comfort level and required us to enhance our communication and teamwork to perform them at a high level. Although the debates were very different from prior years, there was a great sense of accomplishment and satisfaction after they were delivered. Many past cohorts have published guidance documents or statement papers related to their debate topics. ${ }^{1-3}$ The two teams involved in our debate topic have worked together on a manuscript, generating more networking and a great opportunity to better know fellows outside of their teams.

\section{Importance of Activities at the Home Institution}

Participation in the ALFP program is a considerable investment, both financially and in the time commitment for the fellow and college. Creating a plan for local mentorship, topic discussions, and dedicated opportunities to put the leadership lessons learned into practice may be just as important as the actual program itself. The program curriculum is four weeks long, but fellows should expect to invest significantly more time to get the most out of the program. Examples of the additional time commitment include session pre-readings, debate meetings and preparation, local mentorship discussions with college and university level leaders, and a college level leadership project to manage. ${ }^{4}$ The local mentorship discussions with college and university leadership are crucial. They allowed me to discuss what I learned from ALFP, how I could incorporate these lessons into how I lead and afforded me additional feedback on my leadership style from people that have know me for an extended period. With my existing leadership experience being mostly at the college level, discussing how effective leadership is different at the university level was beneficial. It was also very beneficial to have similar discussions with my current college dean and ALFP dean mentor to see how their perspectives differed. It is important to have support from local mentors, and opportunities to put leadership into practice and get feedback at the college level to supplement what is learned in ALFP. Prior fellows and deans who have participated in ALFP can serve as champions to help design a local curriculum for the fellow based on their experiences.

\section{CONCLUSION}

The ALFP program has a long track record of providing excellent leadership preparation and networking opportunities to many of the current leaders in our academy. As of 2017, one fifth of deans and chairs at colleges of pharmacy had participated in ALFP. ${ }^{5}$ However, the ALFP application process is competitive, and only allows for 30 new fellows each year with a maximum of one from each school. The academy needs to continue to work on increasing opportunities for faculty to obtain more formal leadership training, including opportunities for more junior faculty. Professional organizations such as the American College of Clinical Pharmacy and American Society of Health-System Pharmacists offer certificate programs, and sessions for faculty at their annual meetings. ${ }^{6,7}$ The Leadership Development Special Interest Group through AACP also offers professional development for members. Formal leadership training programs and local mentorship are key to growing the future leaders in our profession.

As is true with any leadership program, you get out what you put into it. There were distinct differences in many aspects of the program for Cohort 17, but we were able to adapt our interactions and approach to make it an extremely positive experience. The debates forced everyone out of their comfort zone and taught us leadership and communication 
strategies that we can apply to future leadership tasks that may require a virtual component. It also proved that strong relationships and collaborations can be formed in a virtual setting. Several manuscripts, session proposals, and other collaborations are already in the works. I routinely chat via email or phone with co-fellows about different areas of academia. I know we all are looking forward to getting together in person for our "graduation" and teambuilding activities soon. In summary, the ALFP experience delivered on its expectations, even in a virtual format. Whether offered in-person or virtual in the coming years, this year's cohort proved that the future fellows could have a meaningful experience in a virtual setting. And to answer the question - yes, I would definitely do it again.

\section{REFERENCES}

1. Boerma M, Coyle EA, Dietrich MA, et al. Point/Counterpoint: are outstanding leaders born or made? Am J Pharm Educ. 2017;81(3). doi:10.5688/ajpe81358

2. Pavuluri N, Aparasu RR, Boje KMK, et al. Consideration of aggressive and strategic approaches to address declining enrollment in us pharmacy schools. Am J Pharm Educ. 2019;83(6). doi:10.5688/ajpe6959

3. Ferreri SP, Cross LB, Hanes SD, Jenkins T, Meyer D, Pittenger A. Academic pharmacy: where is our influence? Am J Pharm Educ. 2017;81(4). doi:10.5688/ajpe81463

4. $\quad$ Karimi R. In-House Mentorship. Am J Pharm Educ. 2013;77(3). doi:10.5688/ajpe77364

5. Assemi M, Yu J, Liu S, Corelli RL, Hudmon KS. Educational attainment and academic profile of deans and chairs at us pharmacy schools. Am J Pharm Educ. 2017;81(7). doi:10.5688/ajpe8175928

6. Pharmacy Leadership Academy. Accessed August 7, 2021. https://www.ashpfoundation.org/LeadershipDevelopment/Pharmacy-Leadership-Academy

7. ACCP - Leadership and Management. Accessed August 7, 2021. https://www.accp.com/academy/leadershipAndManagement.aspx 